\title{
Aligning Academic Offerings with Industry Needs and Facility Construction, While Making Space for Relevant Public Private Partnerships (P3s)
}

\author{
Vicki L. Golich, Sandra Haynes, Erin Hillhouse, and David Pfeifer
}

\begin{abstract}
Metropolitan State University of Denver (MSU Denver) has been educating students for Colorado's urban workforce for over fifty years. The following case study of MSU Denver's new Aerospace Engineering Sciences (AES) Building reveals the roles played by partnerships among universities, faculty, and local civic and industry leaders in creating new curricula and facilities. The new Advanced Manufacturing Sciences (AMS) curriculum and specialized labs will be "game changers" for manufacturing in Colorado, because they provide flexible makerspaces that encourage the iterative, changing interaction among students, faculty, and industry essential in an evolving economy. Nurturing such places for collaboration fosters self-sustaining curriculum enrichment.
\end{abstract}

Keywords: Curriculum-workforce alignment; architectural planning and design; alternative revenue streams; project funding

\section{Introduction}

Colorado’s State Assembly established Metropolitan State University of Denver in 1965 to educate Colorado residents. It is the only public, four-year, "access" institution of higher education (IHE) in the state to this day. As a statutorily defined "modified, open enrollment" IHE, MSU Denver accepts any prospective student, who is 20 years old or older and holds a high school degree or GED.

MSU Denver is a commuter school with no residence halls. Over $90 \%$ of its students come from the eight counties surrounding the city; nearly $100 \%$ are Coloradans. Almost one-third of the students are first-generation and Pell-eligible. Well over half are transfer students and the average age is 25 . Over $42 \%$ of MSU Denver's student body are underrepresented minorities and over $26 \%$ are Hispanic, which closely mirrors the demographic changes in the region. The campus is also Colorado's leader in educating students of color in STEM (Science, Technology, Engineering, and Mathematics) fields.

Until 1976, MSU Denver occupied leased space in downtown Denver. Students and faculty ran across major thoroughfares to find classes, earning the mascot name "Roadrunners." In the mid1970s, the State Assembly decided to create a single campus footprint to serve as home to three public IHEs: MSU Denver, the University of Colorado Denver, and the Community College of Denver. Colorado purchased 150 acres in the Auraria neighborhood for the campus. The Auraria Higher Education Council manages the shared facilities and grounds. Although, theoretically, sharing key spaces makes sense, the Council designed Auraria to serve 15,000 students, and, by 2007, enrollments on the three campuses had grown to 40,000-plus students. 
Funding

Perversely, as these enrollments grew, state funding of higher education across the country entered a steep decline with the 2008 "Great Recession.” Colorado followed the same path, affecting every aspect of higher education operations, including deferred maintenance and new capital projects; Colorado now ranks $47^{\text {th }}$ in state funding for higher education (SHEEO, 2017, p. 47). Adding to the overall funding dilemma, MSU Denver is the least well-funded by the state, compared to all other Colorado public IHEs. This inequity exacerbates the fact the MSU Denver charges the lowest tuition and fees in the state (see Table 1).

Table 1. 2017-2018 MSU Denver State Funding, Tuition, and Fees Compared to Other Colorado Public Institutions of Higher Education

\begin{tabular}{llcc} 
Institution of Higher Ed & $\begin{array}{l}\text { State } \\
\text { Support }\end{array}$ & $\begin{array}{l}\text { Tuition \& Fees/ } \\
\text { Semester @ 15 } \\
\text { Hours* }\end{array}$ & $\begin{array}{l}\text { Tuition \& Fees/ } \\
\text { Year @ 30 } \\
\text { Hours* }\end{array}$ \\
Metropolitan State University of Denver & $\$ 3,495$ & $\$ 3,676$ & $\$ 7,353$ \\
University of Northern Colorado & $\$ 5,262$ & $\$ 4,773$ & $\$ 9,545$ \\
University of Colorado (System) & $\$ 4,805$ & $\$ 5,629$ & $\$ 11,258$ \\
Colorado State University (System) & $\$ 6,431$ & $\$ 5,760$ & $\$ 11,519$ \\
\hline
\end{tabular}

* Unlike other IHEs in Colorado, MSU Denver's tuition and fees includes a “window,” so that a student can take up to 18 credit hours for the same cost as 12 credits.

Space Needs

In 2007, MSU Denver reviewed its facilities Master Plan to explore how it might maximize space and teaching capacity. As a result, MSU Denver recommended-and the Auraria campus partners agreed - to build "neighborhoods" on the edges of the campus footprint. Each IHE would still share specific-purpose buildings (e.g., the library and theatre spaces, as well as centrally located general classrooms). Now, each IHE could address unique campus needs. Of course, with state funding constrained, each campus would also have to think creatively about how to pay for new facilities.

For its first project, MSU Denver built its own facility to provide critical, wrap-around student support services in a "one-stop-shop.” The Student Success Building (SSB) is home to everything from admissions to academic advising, the bursar's office and financial aid, tutoring and supplemental instruction. The SSB also provides office space for senior leaders on campus and is home to The Center for Advanced Visualization and Experiential Analysis-a decision theatre used by the community and campus. The administration worked with the students to develop a bond fee paid by students to finance SSB's construction and maintenance.

Second, as a National Collegiate Athletic Association Division II campus, MSU Denver must maintain a certain quality and quantity of facilities for its various athletic teams. Thus, the Regency Athletics Complex (RAC) was born. This unique facility provided a naming (philanthropic) opportunity. Perhaps more importantly, the RAC connects the campus to its 
community in significant ways: The baseball, softball, and soccer fields are available for use by little leagues and community clubs, as is the surrounding track area for walking or jogging.

By 2016, MSU Denver had added 450,000 gross square footage to the university’s inventory, creating more space for programs bursting at the seams for offices, classrooms, and labs.

Public-Private Partnerships (P3s)

As the name suggests, P3s involve a collaboration between at least one public and one private entity to implement and sustain a mutually beneficial, long-term project. P3s come in a wide array of shapes and sizes depending on the goal of the project and the engaged partners. MSU Denver's first foray in to the world of P3s came through its Hospitality, Tourism, and Events Planning (HTE) program. As faculty engaged with industry professionals in the area, they learned that the HTE curriculum needed to include a greater focus on hotel management and craft beer brewing and management. The result? The campus now boasts a full service Marriott Springhill Suites ${ }^{\circledR}$ hotel and a restaurant attached - literally - to the Hospitality Learning Center, 26,000 square feet of classroom and lab. This partnership generates a separate and new stream of revenue to the campus, yielding \$2 million in 2017 to support scholarships and other campus needs.

Similarly, the increasingly popular interest in craft beer brewing led to two new degree programs, one in beer brewing and one in brewpub operations. A P3 with Tivoli Beer Company garnered more space in existing buildings no longer shared with the other campuses along with a modest revenue stream

In a third P3, MSU Denver collaborated with the Detroit Institute of Music Education-yes, in Detroit, Michigan - to offer students degree programs in all aspects of the music industry. This P3 has already grown to include a Denver location, plans to launch new campuses around the country, and promises to generate yet another new stream of revenue.

\section{A New Opportunity: Advanced Manufacturing}

MSU Denver has long had curricular strengths and faculty expertise in aviation and aerospace sciences, engineering, engineering technology sciences, industrial design, computer information systems, and computer science. Therefore, when then-President Barak Obama launched an initiative in 2014 to increase manufacturing in the United States, the faculty were eager to explore how MSU Denver could contribute to the enterprise. The manufacturing sector was booming in Colorado, particularly in the aerospace industry, where it is second only to Texas and surpasses Florida. In consultation with industry leaders, MSU Denver faculty decided to develop an advanced manufacturing degree program.

This multi-step process began by appointing a recently retired faculty member from industrial design, Dr. Ken Phillips, to lead the process. Dr. Phillips was selected for this role because he is highly respected by both faculty and industry leaders. 
Second, the University created an AES Advisory Board, which included representation from Lockheed Martin, Jeppesen, and the Colorado Advanced Manufacturing Alliance to determine specific employer needs. The University invited these and other corporations, which later joined the team, because of their interest in aviation, aerospace sciences, and advanced manufacturing. Employer comments centered on the following:

- Manufacturing job openings were increasing in number, but often went unfilled due to a lack of appropriately educated workers.

- Available curricula focused more on training for lower level jobs via apprenticeships. However, manufacturing jobs were changing in nature and required a different kind of education - one more focused on greater technical expertise (e.g., 3D printing and computer aided manufacturing) and on developing essential $21^{\text {st }}$ Century skills (e.g., teamwork, critical thinking, written and oral communication, and problem solving).

- Since Colorado IHEs were not offering the needed curriculum, mid-level positions were often filled with highly educated and costly engineers recruited from out of state; turnover was high as more advanced positions appropriate to their education became available.

Third, faculty and administrators toured the local advanced manufacturing companies, which expressed interest in the evolving program by responding to an invitation to participate in its development. MSU Denver needed to understand more completely what careers would be available upon graduating with this new degree.

Fourth, they identified, and then toured, three of the best manufacturing educational programs, Ivy Tech, Purdue, and University of Illinois.

Finally, the team conducted two surveys of involved companies regarding job-ready skills needed so they could create a state-of-the-art curriculum. The surveys yielded a strong response, with the following highlights:

- Unanimous support for an AMS degree program, with "essential $21^{\text {st }}$ Century skills” development embedded throughout.

- Consistent need for professional level personnel with a non-engineering bachelor's degree in AMS in the next 5-10 years.

- Overall interest in employees who had hands-on experience with the type of equipment they would be using at work.

- Strong desire for their employees to complete the degree via multiple pathways technical training, apprenticeships, two- and four-year degrees.

A faculty committee set about creating a curriculum responsive to all the information collected from corporate interviews, trips, and surveys. The curriculum development team was led by Dr. Phillips; other team members included Dr. Sandra Haynes, then Dean of the College of Professional Studies; Dr. Joan L. Foster, Dean of the College of Letters, Arts and Sciences; Dr. Jeffrey Forrest, Chair of the Aviation and Aerospace Sciences Department; Dr. Szuzsa Balogh, faculty in Civil Engineering Technology; Dr. Abel Moreno, Chair of the Computer Information Systems and Business Analytics Department; Drs. Aaron Gordon and Jerry Shultz from 
Computer Science; Dr. Duane Swigert from Electrical Engineering Technology; Dr. Ted Shin, Chair of Industrial Design; Drs. Ming Li He and Devi Kalla from Mechanical Engineering Technology, and Dr. Debbie Gilliard, Chair of the Management Department. The collaboration yielded an advanced manufacturing curriculum for a baccalaureate degree with multiple pathways to completion. Once the curriculum won approval, the University launched a search for a permanent Director of the Advanced Manufacturing Sciences Institute to oversee the ongoing work in the Aerospace and Engineering Sciences Building, with a focus on coordinating the efforts of all housed in the building. Dr. Robert Park now serves in this position.

\section{Creating the Right Spaces}

To leverage the collaborative opportunities among local aerospace and advanced manufacturing industries and MSU Denver's related academic programs, the University initiated the Aerospace and Engineering Sciences building project in 2013. Originally, MSU Denver envisioned a funding model equally divided among the state, the University, and philanthropy or other private investments, with each sector contributing \$20M toward an overall project budget of \$60M. However, by early 2014, when it was time to begin the architectural design, the University had not secured financial commitments from the private sector. The focus on advanced manufacturing during this early period may have contributed to the lack of private sector commitment, because this industry relies so heavily on relatively new, small companies. Partnerships for the project would likely not yield foundational-level donations from one or two big companies; instead, MSU Denver would have to look for a larger number of smaller-scale relationships. To fulfill the P3 vision of the project, the partnerships would have to involve a broad group of companies and to engage the specific needs of each company on a one-on-one basis. This meant that the architects had to design a building for an advanced manufacturing curriculum not knowing how much, if any, philanthropic donations would support the final product.

The University engaged the Denver architectural firm Anderson Mason Dale Architects (AMD) to lead the design effort. The emphasis on smaller-scale, alternative partnership opportunities necessitated a rethinking of the architectural project delivery process. The traditional design process is linear in nature, with distinctly separated phases, characterized by one decision leading to the next. Typically, a project begins with a list of space requirements based on program needs, which becomes the basis for the subsequent design phase. However, the funding levels for the AES project were indeterminate at the outset, and the small-scale partnerships targeted by the project were inherently messy: they involved modifying individual spaces to react to different needs from different companies. Opportunities needed to be quickly test-fit with the architecture so that MSU Denver could determine whether the opportunity was worth pursuing. Remaining nimble became the core goal of the design process since a linear, sequential process would not apply.

AMD responded with a flexible approach that overlapped programming and design so that the two activities occurred simultaneously, allowing each activity to influence the other in a nonlinear, iterative way. If an industry partner, such as Lockheed Martin or Hartwig, suggested a certain programming need, AMD quickly evaluated related design implications for MSU 
Denver's consideration. Equally important, if the design unearthed a unique way to utilize a space, that programming opportunity was presented to industry for consideration.

\section{Innovative Partnership Opportunities}

The fluid programming/design process that AMD and MSU Denver prototyped made possible a variety of previously unimaginable innovative partnerships. For example, the project created opportunities for small advanced manufacturing companies to lease business space in the building. By designing the building to be extremely efficient, the project stretched the budget to provide for a whole floor of unfinished shell space. Late in construction, prospective tenants approached MSU Denver with interest in occupying this space. At the time of publication, tenants have leased $100 \%$ of the space. The first to agree to terms was York Space Systems, which makes uniquely designed small satellites. York will establish its satellite production facility and a mission operations center in its leased space. With mentorship from York experts, students will have the opportunity to help design, engineer, and manufacture the satellites. They will also get to operate the spacecraft on orbit and learn how to analyze collected data. Those leasing space get access to University testing equipment and student labor, and the University gets an ongoing revenue stream plus access to critical experiential learning opportunities for students. To date, other entities leasing space include Ambient Energy, EyasSat, and the Colorado Advanced Manufacturing Association (CAMA).

Another example of innovative partnerships in the project is one that developed between MSU Denver and Hartwig, a distributor for advanced manufacturing equipment. Hartwig proposed to loan equipment to the University if, in return, the company could tour potential buyers through the building to see the equipment in use. AMD tested this concept within the building design, and with MSU Denver established what became the Advanced Machines and Robotics Hall, at the front of the building, to house the equipment and act as a showroom for Hartwig. Today, the Hall houses \$2M worth of Hartwig equipment, which will be cycled out on a regular basis, so the University gets access to the most current equipment for students, as well as relief from recurring equipment costs. Hartwig benefits from being able to showcase its newest models for potential buyers and from building familiarity between students and the equipment they will use as they matriculate into the workforce (see Figure 1). 


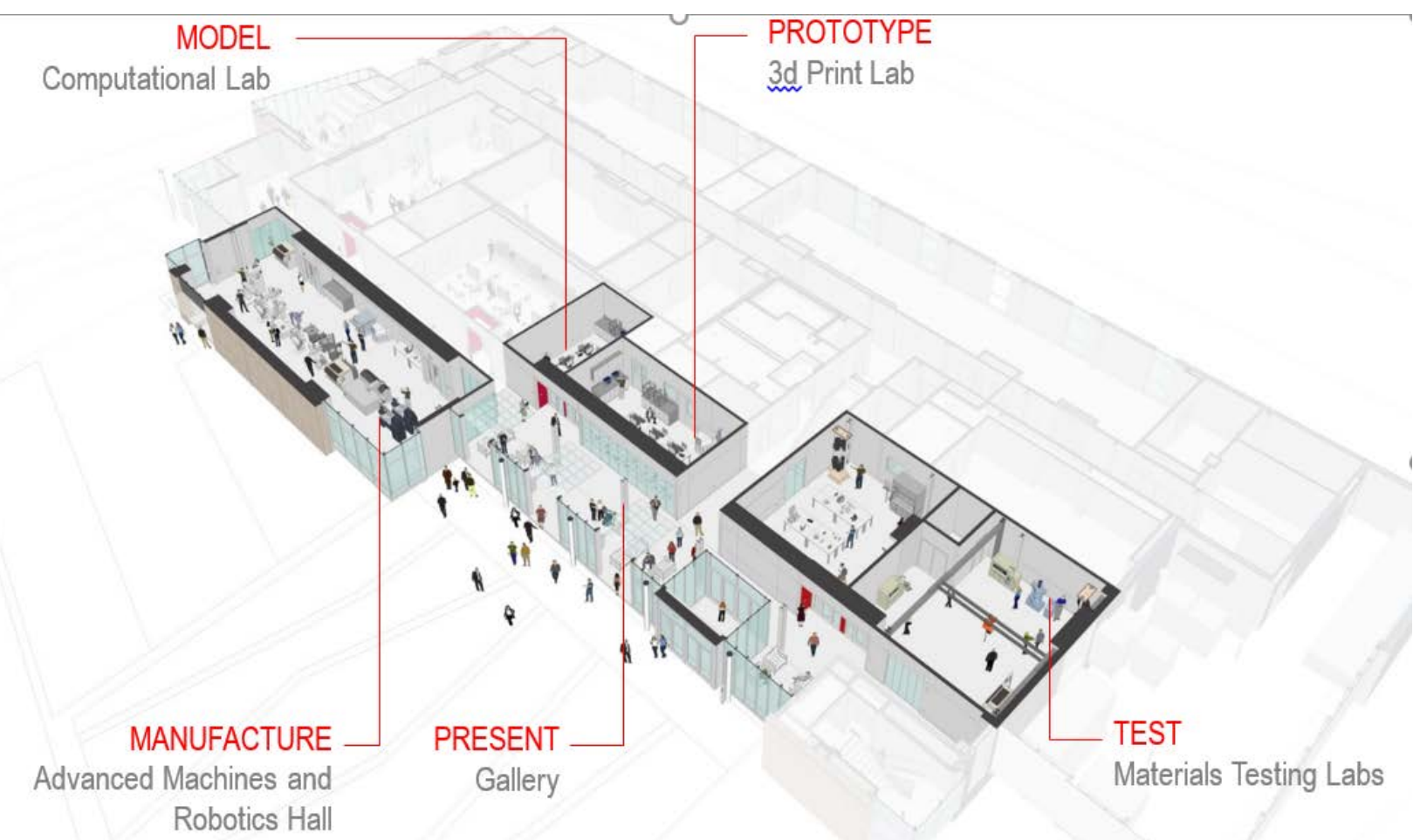

Figure 1. Aerospace \& Engineering Sciences Building advanced manufacturing activities. Advanced Machines and Robotics Hall acts as showroom for Hartwig equipment.

A third partnership leverages the prominence of the site in the city into a shared identity between MSU Denver and the aerospace company Lockheed Martin. The project site lies along an arterial entry into downtown Denver-Auraria Parkway. According to a 2014 traffic study, Auraria Parkway carries 27,000 vehicles per day, which equates to almost 5 million viewings per year of the site. In the early stages of design, the University asked that the façade oriented toward Auraria Parkway visually link MSU Denver with the aerospace industry. Rather than using signage to make this connection in a literal way, AMD proposed that the high-visibility site utilize a two-story student lounge space to house a super-scale aerospace artifact displayed to passing commuters. MSU Denver and Lockheed Martin collaborated to build a half-scale Orion spacecraft mock-up fabricated by students using 3D-printers, which now hangs in the space (see Figure 2). The deepened relationship between MSU Denver and Lockheed eventually became formal with a $\$ 1 \mathrm{M}$ gift from Lockheed to seed the Advanced Manufacturing curriculum in the building. 


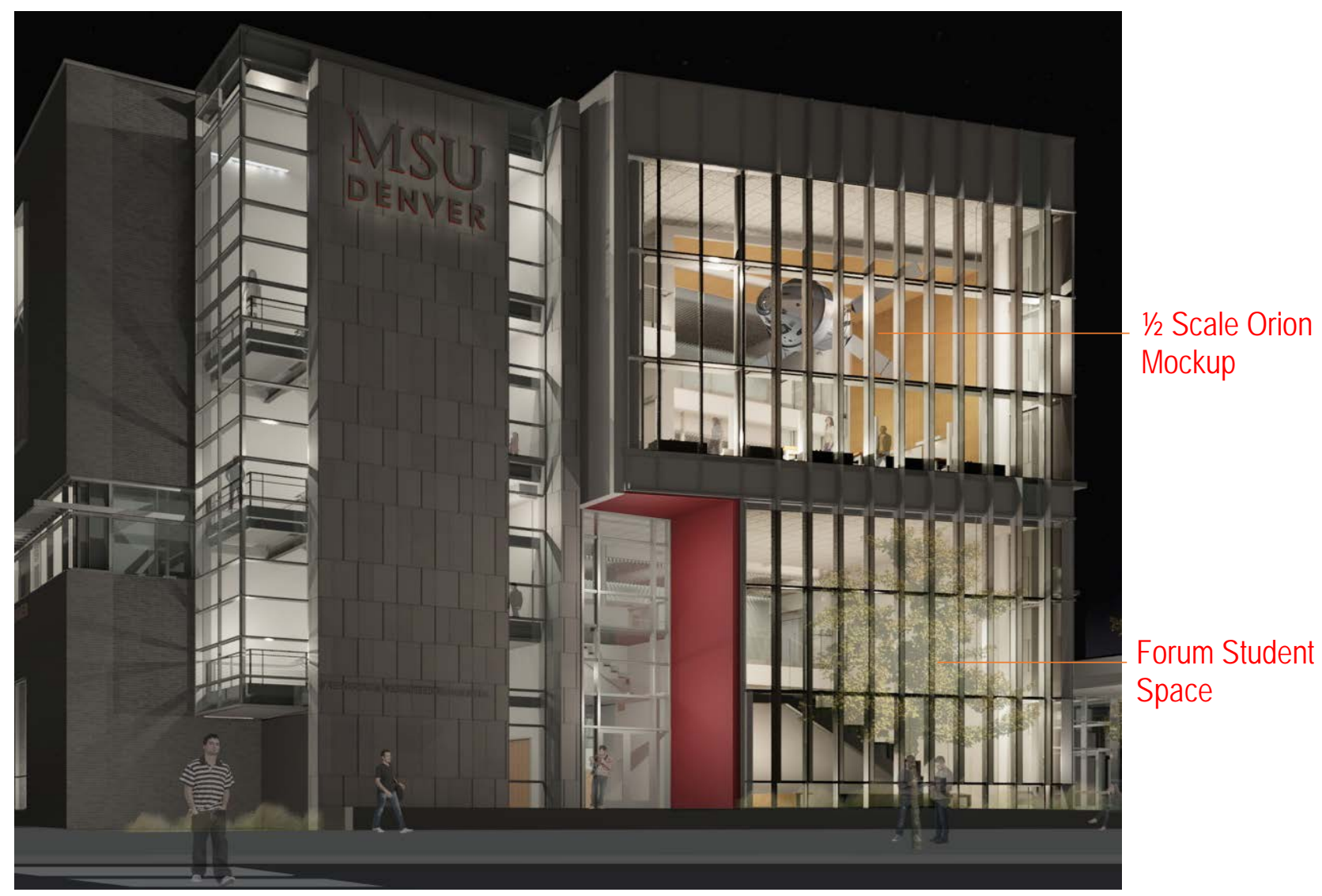

Figure 2. Illustrative drawing of façade facing Auraria Parkway: Orion spacecraft links MSU Denver with Lockheed Martin, manufacturer of the spacecraft and the Forum creates studying and working space for students

\section{Location, Location, Location-Influences Building Design}

As previously noted, the MSU Denver AES building capitalizes on an extraordinary site. The building announces its program to those arriving into and leaving downtown Denver. Thousands of motorists a day pass the side with the city of Denver as a backdrop. MSU Denver is an urban university and the site for the AES building sits precisely on the edge between the campus and the city. These two aspects of the building site drive much of the primary organization and character of the building (see Figure 3). 


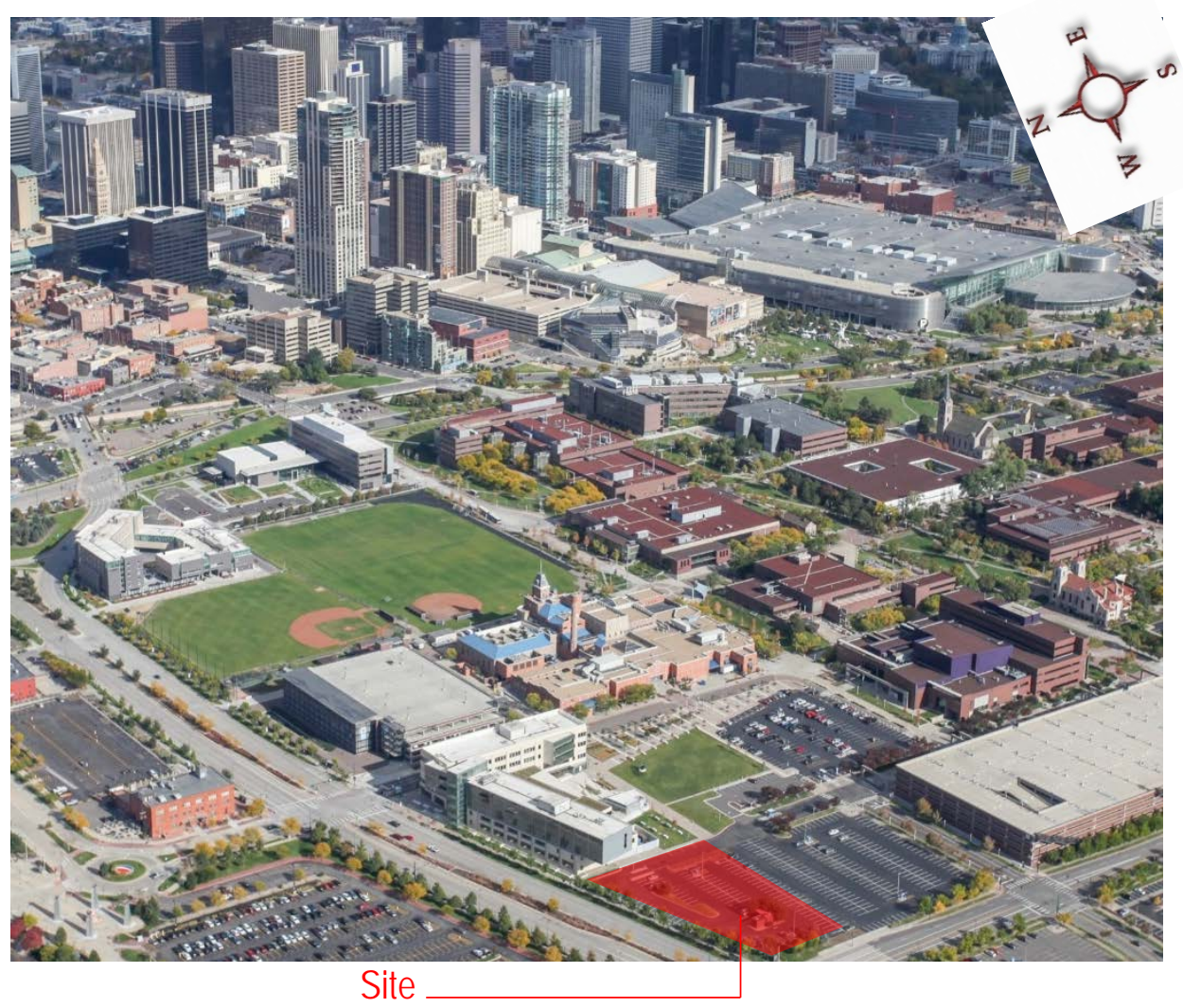

Figure 3. Aerial view of site.

The northern half of the building consists of a series of laboratories, shops and instructional spaces, which present science learning on display to those passing on Auraria Boulevard. The southern edge of the site is the campus edge, the more pedestrian oriented and walkable edge of the site. It is here that the primary student/campus entries occur, and where faculty offices and the Advanced Manufacturing Center are located. Joining these two edges and the plan is a core of instructional spaces and building support zones on all levels (see Figure 4.)

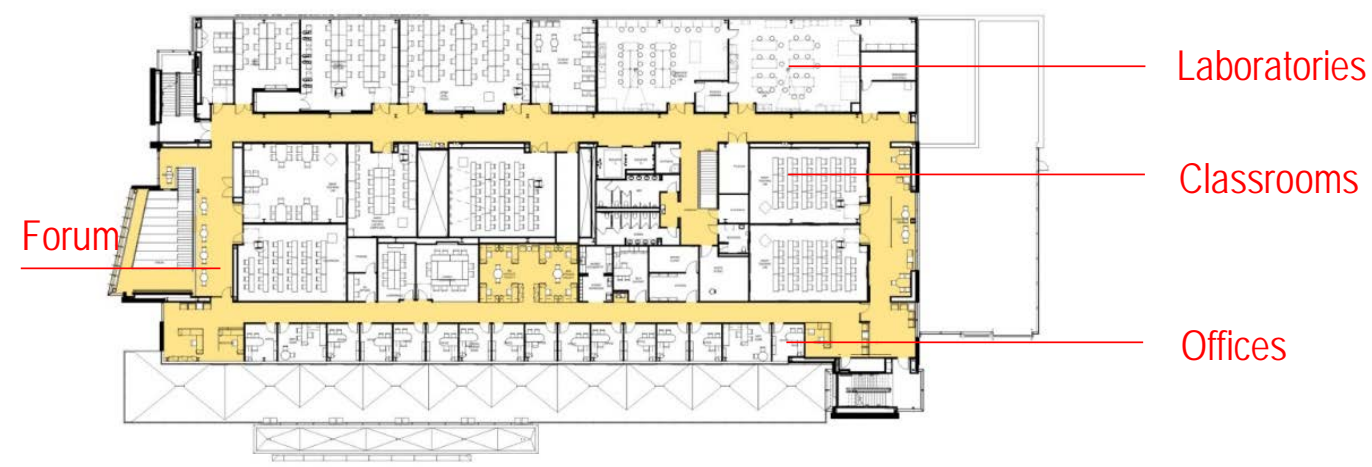

Figure 4. Typical Upper Level Plan 
At the west end of the building, a 'forum' space and a large two-story student lounge and commons, both two-story spaces, look out to the west, to the mountains of Colorado's Front Range in the distance. They provide the beacon and iconic view of the nature of this building for all to see: the Orion mock-up in the two-story student lounge on levels three and four, and the "Forum" on levels one and two for students to study, lounge, listen to special speakers, and other activities.

The Advanced Manufacturing Center on the south side of the building is a highly active and interactive student hub of learning and making. It anchors a gallery where student work is fully on display and where one can see students engaging the robotic equipment in the advanced manufacturing hall or the 3-D printers of the maker spaces, or testing materials in the structural materials testing labs. This gallery opens up to the campus with overhead garage doors such that in pleasant seasons (most of the year in Colorado), the building can be opened up and invite much active pedestrian traffic to and from the campus, celebrating student life and learning and activity (see Figure 5).

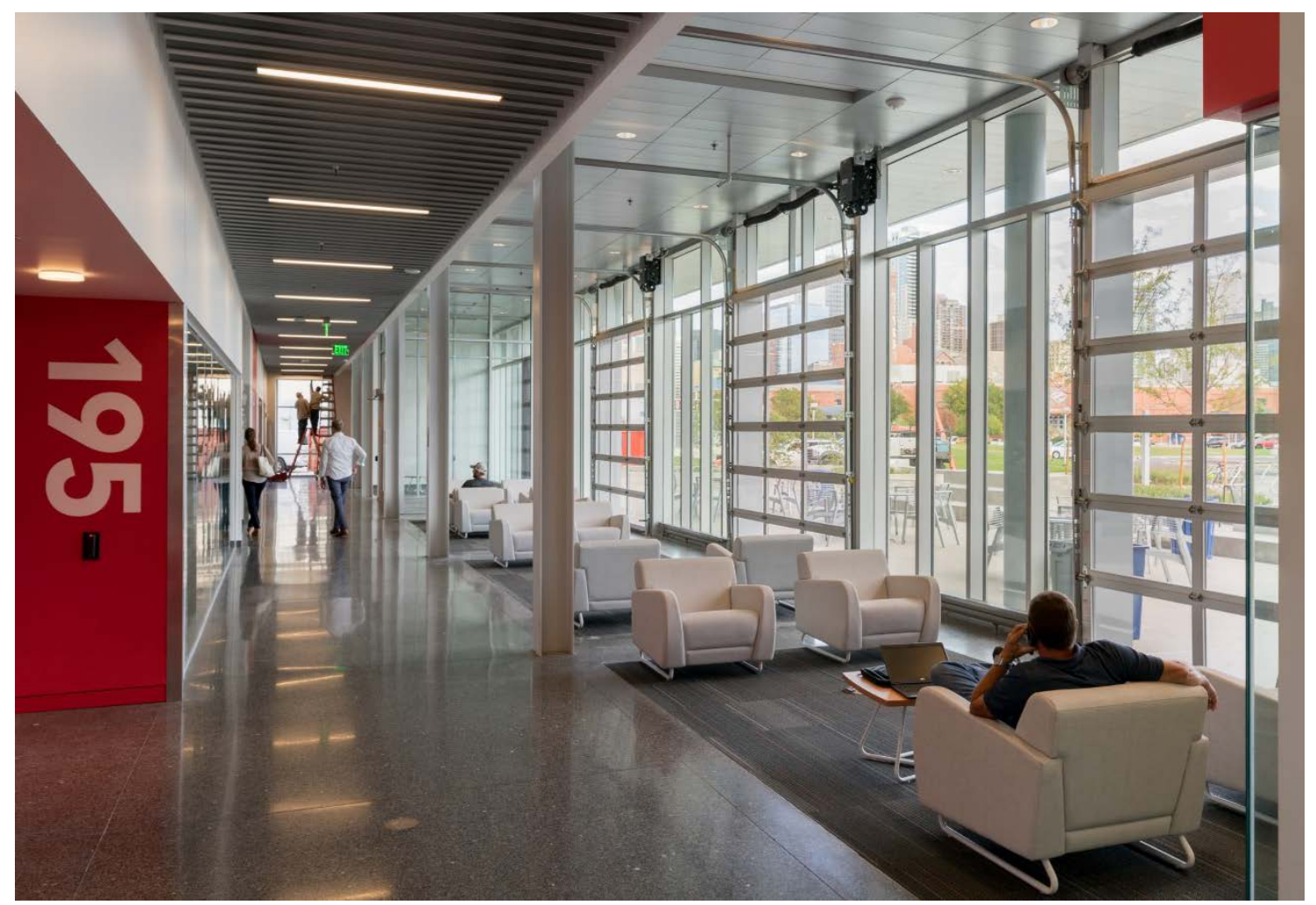

Figure 5. Gallery

The buildings material palette echoes the fabric of existing buildings in the MSU Denver neighborhood. Dark ironspot brick masonry is the primary building material. A textured limestone anchors public points of entry, beacon-like stair towers, and the Advanced Manufacturing Hall. Clear anodized aluminum panels trim public points of entry and canopies 
and projections from the building, lending a machine-like quality and precision evocative of the nature of the work going on within (see Figure 6).

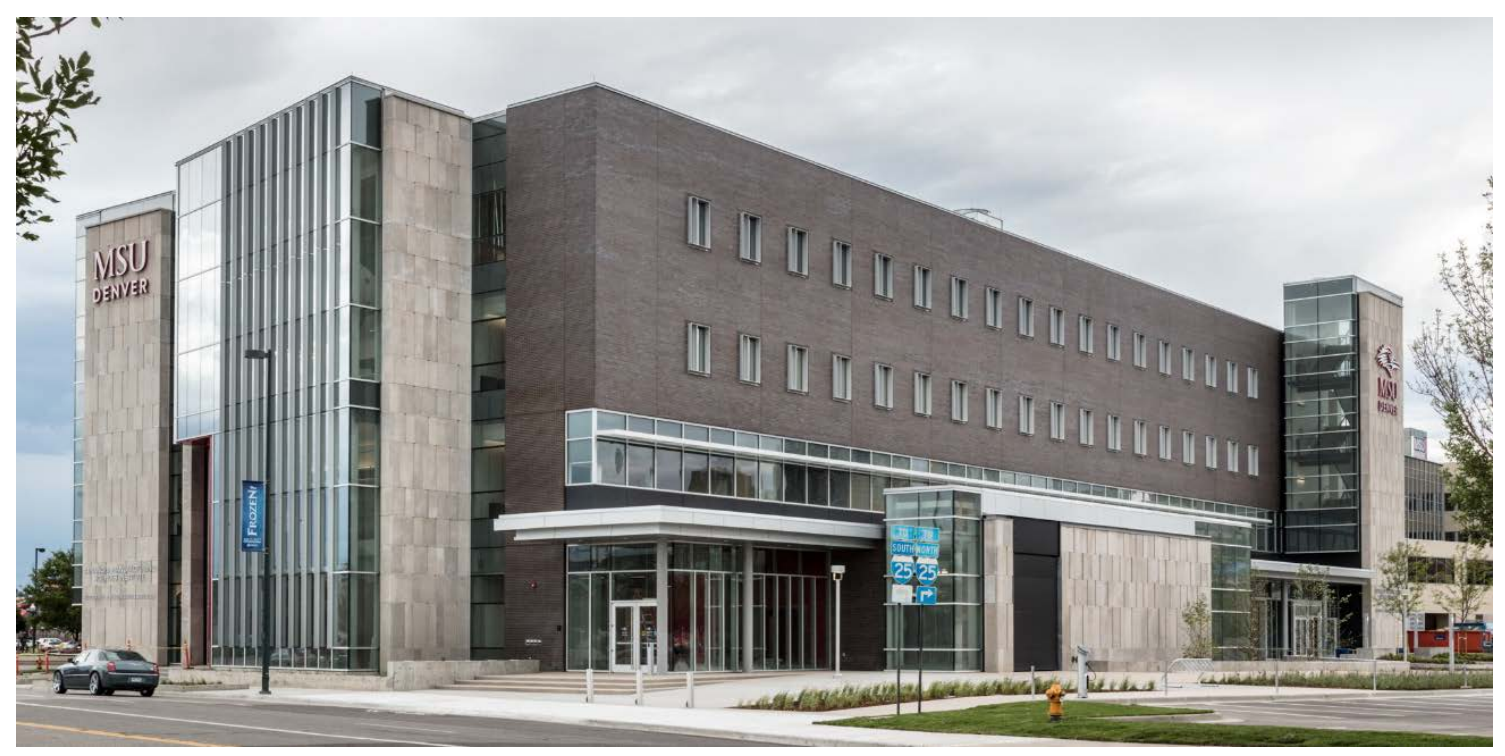

Figure 6. Building Exterior

The completed 117,000 square foot Aerospace and Engineering Sciences Building boasts 90,000 square feet of innovative learning spaces and specialized laboratories that support specific skills and technical expertise. Many of the labs on the first floor have glass walls, which give visitors a peek into the world of advanced manufacturing. Designed with collaboration in mind, the building also has plenty of gathering space for students, faculty, and industry personnel to work together. Three large doors on the south side can open to create an indoor/outdoor classroom or event space. The learning spaces and labs are equipped for experiential learning by students working side-by-side with their faculty. Having access to the Hartwig equipment translates to a highly relevant and targeted educational experience in advanced manufacturing. Revenues from the leased spaces will help to maintain the building, while the corporations and organizations "living" in those spaces will add depth and breadth to critical student experiential learning opportunities.

The academic departments that moved in to the AES building vacated some thirty-seven thousand square feet of space that is now available to other programs, which are at full capacity with student growing demand (e.g., nursing, nutrition, and other allied health programs). MSU Denver is currently planning how to backfill these spaces.

\section{Conclusion}

In today's higher education reality, institutions must develop curricula to meet the needs of the $21^{\text {st }}$ century workforce. This requires constant communication among campus faculty and administrators, as well as with local industry and civic leaders. In addition, learning spaces must be adaptable to $21^{\text {st }}$ century pedagogy that incorporates the latest technology, connect students to 
the "real world," and include hands-on experiences. Where possible, new facilities should be open to creating not only traditional revenue streams — e.g., naming opportunities—but also continuous revenue streams via leases, the production of goods and services, and other innovative partnerships. To create such facilities, it is important to collaborate with architectural firms that are willing and able to adapt their planning, designing, and building processes to meet these needs. This case study provided insight in to one such partnership.

MSU Denver has experienced great success with a variety of P3 opportunities. Each is unique in its partnering strategies, yet each serves the goal of both enhancing student learning and generating additional revenue streams for the University. In some cases, as with the Hotel and Hospitality Learning Center, the revenues add significant resources to support scholarships and other University needs. In others, as with the DIME collaborations, the revenues are more likely to offset the costs of delivering a very expensive curriculum. MSU Denver will continue to pursue P3s; they have proven their value to student learning and the budgetary bottom line. Some future P3s may follow similar constructs to those already in place; others might be innovative in nature. The University welcomes each. 


\section{Reference}

State Higher Education Executive Officers (SHEEO) (2017) SHEF: FY 2016 - State Higher Education Finance. Boulder, CO: Author. 


\section{Author Information}

Vicki L. Golich is Provost and Executive Vice President of Academic and Student Affairs at MSU Denver. She oversees curriculum development and delivery, as well as all wrap around student support services and information technology services. She is actively involved in space planning across the University.

* Vicki L. Golich, Ph.D.

Academic and Student Affairs

Metropolitan State University of Denver

890 Auraria Parkway

Campus Box 48, P.O. Box 173362

Denver, CO 80217-3362

Telephone: 303-615-1900

Email:vgolich@msudenver.edu

Sandra Haynes served as Dean of MSU Denver's College of Professional Studies from 2003 to 2017. In that capacity, she lead or was highly involved in the development of several major P3's on campus, including the Hotel and Hospitality Learning Center, a brewing program, the new athletics complex, One World One Water Center, and the Aerospace Engineering Sciences Building. She subsequently served as MSU Denver's Deputy Provost and oversaw all of Academic Affairs. She is currently Chancellor of Washington State University Tri-Cities.

Sandra Haynes, Ph.D.

Chancellor

Washington State University Tri-Cities

2710 Crimson Way

Richland, WA

Telephone: 509-372-7000

Email: Sandra.Haynes@wsu.edu

Erin Hillhouse is a Senior Associate at Anderson Mason Dale Architects (AMD). He joined AMD in 2006 and has 20 years of experience with an extensive background in large and complex projects for higher education. Since joining AMD, Erin has developed a focus on facilities for engineering education. He has led significant projects of this type at several Universities. Several publications, including Metropolis and Architectural Review, have recognized Erin's projects for design excellence.

Erin Hillhouse

Senior Associate

Anderson Mason Dale Architects

3198 Speer Boulevard

Denver, CO 80211

Telephone: 303-294-9448

Email: ehillhouse@amdarchitects.com 
David Pfeifer has been a Partner at Anderson Mason Dale Architects (AMD) for 15 years. He has worked extensively on higher education campuses throughout Colorado and the Rocky Mountain West. On the Auraria campus in downtown Denver, home to MSU Denver, David served as the design principal for AMD on the MSU Denver's AES Building, the Auraria Higher Education Center Science Building Addition and Renovation. He is the Principal in Charge on the University of Colorado Denver Student Commons Building (completed) and Student Wellness Center (under construction) on the Auraria campus.

David Pfeifer

Principal

Anderson Mason Dale Architects

3198 Speer Boulevard

Denver, CO 80211

Telephone: 303-294-9448

Email: dpfeifer@amdarchitects.com

* Corresponding author 